\title{
Comprehensive analysis of human papillomavirus prevalence and the potential role of low-risk types in verrucous carcinoma
}

\author{
Marta del Pino ${ }^{1}$, Maaike CG Bleeker ${ }^{1}$, Wim G Quint ${ }^{2}$, Peter JF Snijders ${ }^{1}$, \\ Chris JLM Meijer ${ }^{1}$ and Renske DM Steenbergen ${ }^{1}$ \\ ${ }^{1}$ Unit of Molecular Pathology, Department of Pathology, VU University Medical Center, Amsterdam, \\ The Netherlands and ${ }^{2} D D L$ Diagnostic Laboratory, Voorburg, The Netherlands
}

\begin{abstract}
The role of human papillomavirus (HPV) infections in the development of verrucous carcinoma, a welldifferentiated variant of squamous cell carcinoma with difficult differential diagnosis, is controversial in the literature. In this study, we analysed verrucous carcinoma from different origins for the presence and activity of a broad spectrum of HPV types, and carefully reviewed the histopathological features. A random series of 27 formalin-fixed, paraffin-embedded specimens of verrucous carcinoma was taken, representing the head and neck region $(n=6)$, anogenital area $(n=16)$ and extragenital skin region $(n=5)$. After review of the histological slides, all samples were subjected to different polymerase chain reaction-based HPV detection techniques, together detecting a total of $83 \mathrm{HPV}$ types, including both mucosal and cutaneous types. Histological revision was carefully performed. Lesions with keratinised papillae, blunt stromal invaginations and minimal cytological atypia were considered verrucous carcinoma. Condylomatous lesions with viral changes were defined as giant condyloma. Verrucous lesions that did not meet those criteria were classified as verrucous hyperplasia. Tumours with stromal infiltration were considered as invasive squamous cell carcinoma. Histological revision revealed that 13 out of 27 cases were verrucous carcinoma (one showing a double infection with HPV 35 and 45 ), 5 invasive squamous cell carcinomas, 5 verrucous hyperplasia (one with a double infection with HPV 4 and 8), 1 pseudoepitheliomatous hyperplasia and 3 giant condylomas. All three giant condylomas were low-risk HPV positive (HPV 6 and 11) and showed active mRNA transcription. None of the HPV-positive samples tested positive for diffuse p16 ${ }^{\text {INK4A }}$ staining. In conclusion, our results do not support a causal role of HPV in the development of verrucous carcinoma. Testing for LR-HPV, particularly HPV 6 and 11, may help in the differential diagnosis of lesions suspicious of verrucous carcinoma as those testing positive for LR-HPV most likely represent giant condylomas.

Modern Pathology (2012) 25, 1354-1363; doi:10.1038/modpathol.2012.91; published online 8 June 2012
\end{abstract}

Keywords: E6 expression; human papillomavirus; $\mathrm{p} 16^{\text {INK4A }}$ staining; verrucous carcinoma

Verrucous carcinoma is a low-grade, well-differentiated variant of squamous cell carcinoma that was first described by Ackerman in 1948. ${ }^{1}$ Verrucous carcinoma typically presents as a slowly enlarging verrucous tumour showing a 'pushing' border that compresses the surrounding tissue without true stromal invasion. ${ }^{2}$ Verrucous carcinoma has a benign histopathological appearance with minimal

Correspondence: RDM Steenbergen, PhD, Unit of Molecular Pathology, Department of Pathology, VU University Medical Center, CCA1.18, PO Box 7057, 1007 MB Amsterdam, The Netherlands.

E-mail: r.steenbergen@vumc.nl

Received 16 December 2011; revised 21 January 2012; accepted 21 January 2012; published online 8 June 2012 atypia and few mitotic cells, but behaves locally destructive and seldom has lymph node metastasis.

Because of the absence of epithelial dysplasia and the absence of stromal invasion in the initial phases, most cases are not recognized as being malignant. Therefore, awareness of both the clinician and pathologist is crucial for appropriate diagnosis of verrucous lesions, including the spectrum of verrucous hyperplasia, verrucous carcinoma and stromal invasive squamous cell carcinoma. ${ }^{3}$ Verrucous carcinoma was originally described as an oral lesion, but subsequent reports identified additional epithelial sites of development, such as skin and anogenital regions. Beside the spectrum of verrucous hyperplasia towards invasive squamous cell carcinoma, other neoplastic lesions like 'giant 
condyloma' in the anogenital region may show both clinical and histopathological similarities with verrucous carcinoma. Finally, non-neoplastic lesions like lichen simplex chronicus and pseudoepitheliomatous hyperplasia may be considered in the differential diagnosis. ${ }^{2}$

The pathogenesis of verrucous carcinoma is uncertain. ${ }^{4-6}$ Oral verrucous carcinoma has been associated with the chronic use of tobacco or with the practice of chewing betel nuts, ${ }^{7}$ ultraviolet radiation has been associated with verrucous carcinoma arising from the $\operatorname{skin}^{8}$ and chronic lesions like squamous cell hyperplasia and lichen sclerosus have been related to vulvar verrucous carcinoma development. ${ }^{9}$ More recent studies suggest a potential role for human papillomavirus (HPV) in the pathogenesis of verrucous carcinoma, although the literature data are controversial. ${ }^{10,11}$

HPV are non-enveloped, double-stranded DNA viruses belonging to the family of Papillomaviridae. ${ }^{12}$ Papillomaviruses infect epithelial cells and are subdivided into cutaneous and mucosal types. Cutaneous types have been related to both benign skin lesions and non-melanoma skin cancers. ${ }^{13}$ Mucosal HPV types can be found in the epithelial linings of the anogenital, respiratory and upper digestive tracts and are classified as low- or highrisk HPV according to their oncogenic potential. ${ }^{14,15}$ Infections with low-risk types are generally linked to benign wart-like lesions, most of them without risk of carcinogenic transformation. However, occasionally low-risk HPV types have been detected in malignant lesions, such as penile carcinomas. ${ }^{16-18}$ Infection with high-risk HPV has been associated with malignant transformation, and causally related to cervical cancer ${ }^{19,20}$ and a subset of squamous cell carcinomas in the head and neck and anogenital region different from the cervix. ${ }^{21-23}$

Verrucous carcinoma has been associated with both low-risk (types 6 and 11) and high-risk (types 16 and 18) types of HPV. ${ }^{18,24,25}$ However, a causal relationship between HPV and verrucous carcinoma remains to be proven, specifically in those cases in which a low-risk HPV has been suggested to be involved in the genesis of the tumours. ${ }^{5,26}$

Some authors have considered verrucous carcinoma and giant condyloma as a spectrum of the same process mainly due to the overlapping histological features ${ }^{27}$ suggesting that verrucous carcinoma may evolve from a persistent irritated condyloma. In those cases, low-risk HPV types may initiate the growth process and the chronic epithelial irritation could subsequently contribute to the development of a malignant phenotype. ${ }^{9}$

The aim of this study was to analyse comprehensively verrucous carcinoma from different origins, that is, head and neck region, the anogenital area and extragenital skin for the presence of HPV, including both mucosal and cutaneous types, and to carefully review the histopathological diagnosis. Cases testing positive for low-risk HPV were also examined for viral E6 mRNA expression and p16 ${ }^{\text {INK4a }}$ staining to determine their potential contribution to tumour development.

\section{Materials and methods}

\section{Patients and Tissue samples}

In all, 27 formalin-fixed, paraffin-embedded originally diagnosed verrucous carcinoma from head and neck region $(n=6)$, the anogenital area $(n=16)$ and the extragenital skin region $(n=5)$ were selected from the archives of the Department of Pathology at the VU University Medical Center in Amsterdam, taking into account availability of the blocks. All diagnoses were initially made between 1988 and 2009. All slides were independently reviewed by two pathologists (CM and $\mathrm{MB}$ ) for consensus diagnosis and to ascertain the presence of a lesion in the sections used for HPV analysis. The revision was performed without knowing the HPV status of the samples. Verrucous carcinoma was defined as a squamous tumour with thick, heavily keratinised papillae and blunt, broad stromal invaginations of well-differentiated squamous cells with minimal cytological atypia and rare mitosis extending into the underlying stroma with broad pushing rather than infiltrating border. Giant condyloma was defined as a verrucous tumour with condylomatous appearance and viral changes, including koilocytosis (perinuclear cytoplasmic clearing with peripheral condensation of the cytoplasm) and significant cytonuclear changes such as irregular nuclear contours, hyperchromasia and binucleation/multinucleation. Verrucous lesions that did not meet the criteria for verrucous carcinoma or condyloma were classified as verrucous hyperplasia. Tumours with destructive stromal infiltration were considered as invasive squamous cell carcinoma.

Two formalin-fixed, paraffin-embedded condylomata acuminata with a single HPV 6 infection were included as controls for transcription analysis. Table 1 shows the clinicopathological data of the selected tissue samples.

\section{Tissue Preparation and Nucleic-Acid Isolation}

Formalin-fixed, paraffin-embedded samples were serially sectioned (10 sections $\times 10 \mu \mathrm{m}$ ) on a microtome.

The first and last sections $(3 \mu \mathrm{m})$ were H\&E stained for histomorphological confirmation of tumour presence. In-between sections were collected in RNAsefree reaction tubes (one for DNA isolation and one for RNA isolation). Sectioning and sample preparation were carried out with the highest measures to avoid contamination and cross-contamination. Paraffin blocks lacking tissue were cut in-between the patient samples as controls to assure the lack of contamination. None of these control samples were positive in the HPV polymerase chain reaction 
Table 1 Overview of clinicopathological data of verrucous lesions analysed

\begin{tabular}{|c|c|c|c|c|c|c|}
\hline ID & Sex & Age (years) & Location & Original diagnosis & Consensus diagnosis & HPV status \\
\hline 1 & Female & 78 & Vulva & Verrucous carcinoma & Verrucous carcinoma $^{\mathrm{a}}$ & Negative \\
\hline 2 & Female & 82 & Anus & Verrucous carcinoma & Invasive squamous cell carcinoma & Negative \\
\hline 3 & Male & 34 & Anus & Verrucous carcinoma & Giant condyloma $^{\mathrm{a}}$ & HPV 6 \\
\hline 4 & Female & 70 & Vulva & Verrucous carcinoma & Verrucous carcinoma & Negative \\
\hline 5 & Female & 88 & Vulva & Verrucous carcinoma & Invasive squamous cell carcinoma & Negative \\
\hline 6 & Female & 74 & Vulva & Verrucous carcinoma & Invasive squamous cell carcinoma & Negative \\
\hline 7 & Male & 78 & Penile & Verrucous carcinoma & Verrucous hyperplasia & HPV 4,8 \\
\hline 8 & Female & 78 & Vulva & Verrucous carcinoma & Invasive squamous cell carcinoma & Negative \\
\hline 9 & Female & 61 & Perineum & Verrucous carcinoma & Giant condyloma $^{\mathrm{a}}$ & HPV 6 \\
\hline 10 & Male & 66 & Penile & Verrucous carcinoma & Verrucous hyperplasia & Negative \\
\hline 11 & Male & 50 & Penile & Verrucous carcinoma & Verrucous hyperplasia & Negative \\
\hline 12 & Female & 52 & Skin & Verrucous carcinoma & Verrucous hyperplasia & Negative \\
\hline 13 & Female & 81 & Vulva & Verrucous carcinoma & Invasive squamous cell carcinoma & Negative \\
\hline 14 & Female & 80 & Vulva & Verrucous carcinoma & Giant condyloma $^{\mathrm{a}}$ & HPV 11 \\
\hline 15 & Female & 94 & Vulva & Verrucous carcinoma & Verrucous carcinoma $^{\mathrm{a}}$ & Negative \\
\hline 16 & Female & 59 & Head and neck & Verrucous carcinoma & Verrucous carcinoma & HPV 35,45 \\
\hline 17 & Female & 92 & Vulva & Verrucous carcinoma & Verrucous carcinoma $^{a}$ & Negative \\
\hline 18 & Male & 39 & Head and neck & Verrucous carcinoma & Verrucous carcinoma & Negative \\
\hline 19 & Male & 57 & Head and neck & Verrucous carcinoma & Verrucous hyperplasia & Negative \\
\hline 20 & Male & 68 & Skin & Verrucous carcinoma & Verrucous carcinoma & Negative \\
\hline 21 & Female & 50 & Vulva & Verrucous carcinoma & Verrucous carcinoma & Negative \\
\hline 22 & Female & 68 & Skin & Verrucous carcinoma & Verrucous carcinoma & Negative \\
\hline 23 & Female & 79 & Head and neck & Verrucous carcinoma & Verrucous carcinoma & Negative \\
\hline 24 & Male & 76 & Skin & Verrucous carcinoma & Verrucous carcinoma & Negative \\
\hline 25 & Female & 64 & Head and neck & Verrucous carcinoma & Verrucous carcinoma & Negative \\
\hline 26 & Male & 58 & Skin & Verrucous carcinoma & Pseudoepitheliomatous hyperplasia & Negative \\
\hline 27 & Male & 66 & Head and neck & verrucous carcinoma & Verrucous carcinoma & Negative \\
\hline 28 & Female & 33 & Vulva & Condyloma acuminata & Condyloma acuminata & HPV 6 \\
\hline 29 & Female & 21 & Vulva & Condyloma acuminata & Condyloma acuminata & HPV 6 \\
\hline
\end{tabular}

${ }^{\mathrm{a} C y t o m o r p h o l o g i c a l ~ s i g n s ~ o f ~ v i r a l ~ a c t i v i t y ~(i e ~ k o i l o c y t o s i s, ~ d o u b l e ~ n u c l e i, ~ c o u r s e ~ g r a n u l a) . ~}$

(PCR) assay, indicating adequate avoidance of contamination.

DNA extraction was performed by incubation of deparaffinised sections in $0.1 \mathrm{mg} / \mathrm{ml}$ proteinase $\mathrm{K}$ solution overnight at $55{ }^{\circ} \mathrm{C}$. Subsequently, proteinase $\mathrm{K}$ was heat-inactivated by incubation of the sections at $100{ }^{\circ} \mathrm{C}$ for $10 \mathrm{~min}$, and samples were spun down and cooled down at $-20^{\circ} \mathrm{C}$ for $1-2 \mathrm{~min}$. DNA was isolated using NucliSens easyMAG platform isolation system (bioMérieux, Boxtel, The Netherlands), according to the manufacturer's instructions.

RNA was isolated by digestion of deparaffinised sections in $0.1 \mathrm{mg} / \mathrm{ml}$ proteinase $\mathrm{K}$ solution overnight at $52{ }^{\circ} \mathrm{C}$, followed by RNA extraction with TRIzol reagent (Invitrogen, Carlsbad, CA, USA), according to the manufacturer's protocol. The final RNA pellet was washed twice with $200 \mu \mathrm{l}$ of $70 \%$ ethanol, air-dried and re-suspended in $20-50 \mu \mathrm{l}$ of RNAse/DNase free water.

DNA and RNA yields were quantified spectrophotometrically using the Nanodrop ND-1000 (Isogen Life Science, IJsselstein, The Netherlands).

\section{HPV DNA Detection and Typing}

To assess the quality of the DNA, $\beta$-globin PCR analysis was performed using the primers BGPCO3 and BGPCO5 as described previously. ${ }^{28}$ The PCR products were analysed by electrophoresis on a $1.5 \%$ agarose gel. All samples were $\beta$-globin PCR-positive, indicating adequate sample quality.

Mucosal HPV DNA was detected by the L1-regionbased, GP $5+/ 6+$ PCR as described by Jacobs et al. ${ }^{29}$ Mucosal HPV DNA were typed by Reverse Line Blot (RLB) as described previously. ${ }^{30}$ This system allows the typing of both high-risk HPV (types 16, 18, 26, 30, 31, 33, 35, 39, 45, 51, 52, 56, 58, $59,66,68,70,73,82 \mathrm{i}$ and $82 \mathrm{~m}$ ) and low-risk HPV $(6,11,34,40,42,43,44,54,55,57,61,64,71,72,81$ and CP6108).

In addition, we used the SPF10-LiPA system (SPF10 HPV LiPA, version 1; Labo Bio-Medical Products, Rijswijk, The Netherlands), as described previously, ${ }^{31,32}$ to test for the presence of the remaining low-risk HPV types HPV 53 and 74.

Cutaneous HPV DNA were detected and typed by L1-region-based BGC-HPV PCR-RLB as described previously, ${ }^{33}$ detecting $24 \beta$ and $\gamma$ HPV types (HPV types $4,5,8,9,12,14,15,17,19,20,21,22,23,24$, $25,36,37,38,47,48,49,50,60$ and 65). Additional cutaneous types $1,2,3,7,10,27,28,29,40,41,43$, $57,63,75,76,77,80,88,91,92,93,94,95$ and 96 were tested for using the PM-PCR reverse hybridization assay method (Diassay BV, Rijswijk, The Netherlands) as described by de Koning et al. ${ }^{9}$ All samples were tested in duplicate and all duplicate assays were highly $(25 / 27 ; 92.6 \%)$ concordant both with respect to HPV positivity and typing results. 
Table 2 Primers designed to detect E6 mRNA expression of the low-risk HPV types

\begin{tabular}{|c|c|c|c|}
\hline HPV type & Sequence & Target gene & Amplicon size (bp) \\
\hline HPV6 & F: $5^{\prime}$-GTGCAAGACGTTTAATCTATCTATGC-3' & E6 & 91 \\
\hline HPV11 & $\begin{array}{l}\text { F: 5'-CACACTCTGCAAATTCAGTGCG-3' } \\
\text { R: 5'-CACACAACCTTTAGGTTCTTATAGGC-3' }\end{array}$ & E6 & 92 \\
\hline snRNP U1A & $\begin{array}{l}\text { F: 5'-CAGTATGCCAAGACCGACTCAGA-3' } \\
\text { R: 5'-GGCCCGGCATGTGGTGCATAA-3' }\end{array}$ & Housekeeping gene & 215 \\
\hline
\end{tabular}

F, forward; R, reverse.

The U1 small nuclear ribonucleoprotein-specific A protein was included as a quality control of the procedure.

\section{Reverse transcriptase-PCR}

Before reverse transcriptase-PCR (RT-PCR) analysis, RNA samples were RQ1-DNAse-treated according to the manufacturer's recommendations (Promega, Leiden, The Netherlands). Subsequently, reverse transcription using AMV RT (Promega) of RNA into cDNA was performed essentially as described before. $^{34}$ A reaction without RT was run in parallel for each specimen to control for DNA contamination.

To assess the quality of all RNA specimens, RTPCR for the housekeeping gene encoding the U1 small nuclear ribonucleoprotein-specific A protein (snRNP U1A, $215 \mathrm{bp}$ ) was performed. Primers, annealing temperature and amplicon length are listed in Table 2.

\section{Immunohistochemical staining for $\mathrm{p} 16^{\mathrm{INK} 4 \mathrm{a}}$}

Immunohistochemical analysis for $\mathrm{p} 16^{\text {INK4a }}$ was performed on all the HPV-positive samples. First, sections from formalin-fixed, paraffin-embedded tissues and appropriate positive and negative control tissues were deparaffinised. Then, for all samples, endogenous peroxidase activity was blocked by incubating sections in hydrogen peroxide. Antigen retrieval was performed by heating at $100{ }^{\circ} \mathrm{C}$ for $15 \mathrm{~min}$ in $10 \mathrm{mM}$ sodium citrate buffer $(\mathrm{pH}$ $6.0)$ in a microwave oven $(600 \mathrm{~W})$. After blocking of nonspecific binding by pre-incubation with normal rabbit serum, sections were incubated with primary monoclonal antibodies against p16 ${ }^{\text {INK4a }}$ (CINtec clone ink4a; MTM Laboratories Heidelberg, Germany). Biotinylated rabbit anti-mouse Fab fragment was applied as a secondary antibody for $1 \mathrm{~h}$, followed by incubation with avidin-biotin complex.

Signals were detected using diaminobenzidine and the sections were counter-stained with haematoxylin. Sections treated with PBS instead of the primary antibody were used as negative controls. Cervical carcinoma sections were included in each staining experiment as positive controls for $\mathrm{p} 16^{\mathrm{INK} 4 \mathrm{a}}$.

\section{Results}

\section{HPV detection}

To analyse comprehensively the presence of HPV, we applied four different PCR-based techniques allowing the detection of a total of $83 \mathrm{HPV}$ types, including both mucosal and cutaneous types. HPV DNA, as a single or multiple infection, was detected in $18.5 \%(5 / 27)$ of the lesions analysed, and included low-risk HPV, high-risk HPV and cutaneous HPV types.

Revision revealed that 13 lesions were compatible with verrucous carcinoma, 5 with stromal invasive squamous cell carcinoma and 5 with verrucous hyperplasia. Giant condylomas were diagnosed in 3 cases and 1 case showed pseudoepitheliomatous hyperplasia. Taken both results together, all 3 giant condylomas were low-risk HPV positive, 2 anal lesions containing HPV 6 and the giant condyloma of the vulva containing HPV 11. A double infection with HPV 35 and 45 was found in 1 (1/13) verrucous carcinoma, which was located in the oral cavity and a double infection with HPV 4 and 8 was detected in $1(1 / 5)$ verrucous hyperplastic lesion located in the penis. All invasive squamous cell carcinomas and the pseudoepitheliomatous hyperplastic lesion were HPV negative. Table 1 shows the HPV detection and typing results in relation to the histopathological diagnosis of all samples. In Figure 1 representative photographs of the different lesions are shown.

\section{E6 mRNA expression}

As all samples positive for low-risk HPV were upon review diagnosed as giant condylomas, which has previously been suggested as a starting point of verrucous carcinoma development, ${ }^{9,27}$ we next measured HPV E6 mRNA expression in these samples to determine viral activity. We included two HPV 6positive condylomata acuminata as controls for transcriptional assays.

RT-PCR analysis revealed E6 mRNA expression in all 3 giant condylomas and both control condylomata acuminata (Figure 2).

\section{p16 $^{\text {INK4a }}$ immunostaining}

To determine the presence of a so-called transforming infection, as is particularly seen in high-grade premalignant cervical lesions and cancers associated with a high-risk HPV infection, we subjected all samples testing positive for HPV to $\mathrm{p} 16^{\mathrm{INK} 4 \mathrm{~A}}$ staining. The low-risk HPV-positive samples either 

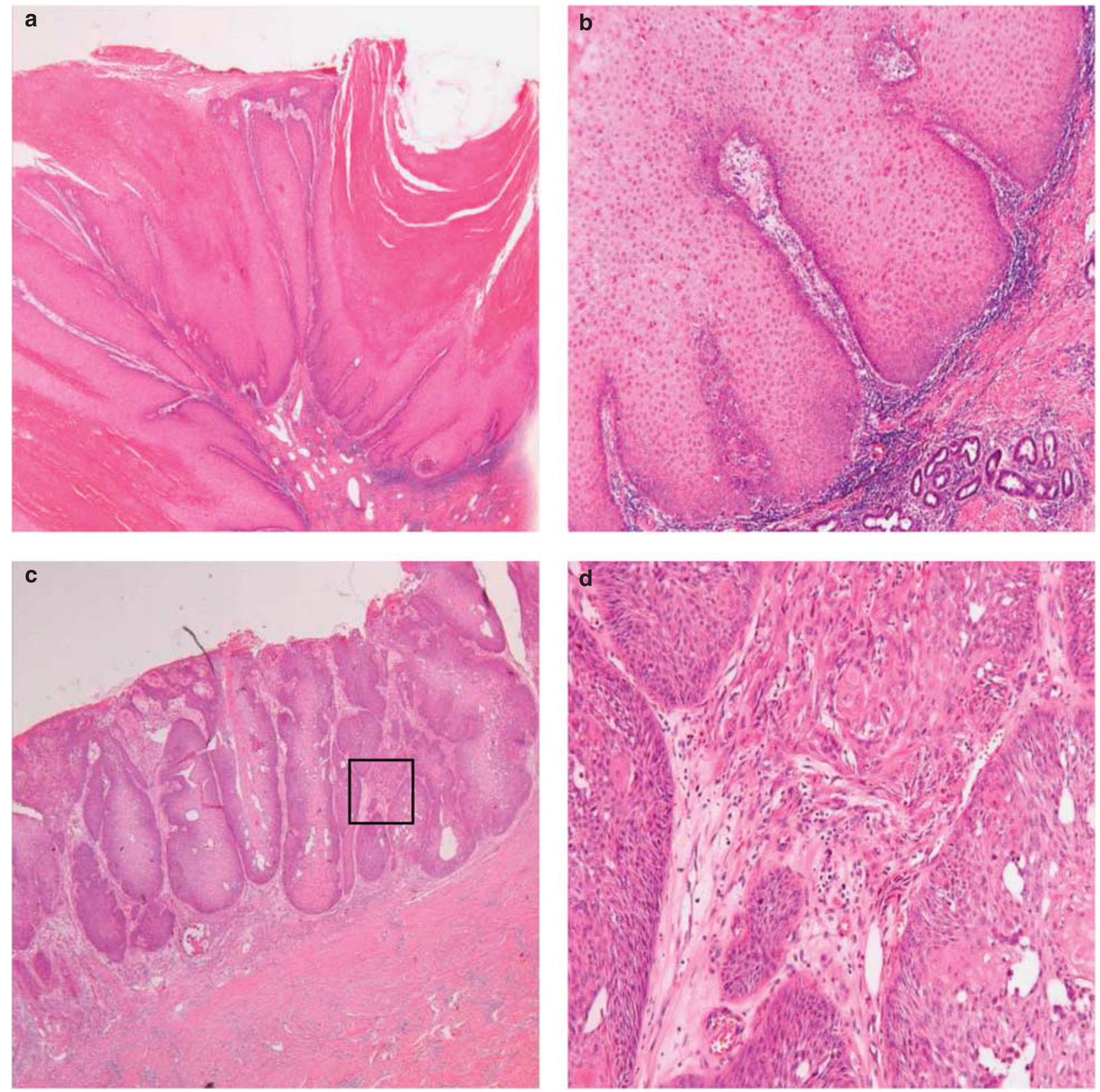

Figure 1 Verrucous carcinoma is a verrucous tumour with blunt broad stromal invaginations of well-differentiated squamous cells with minimal cytological atypia and rare mitosis extending into the underlying stroma with broad pushing rather than infiltrating border (a, b). Invasive squamous cell carcinoma present with destructive stromal infiltration (c, d). Giant condyloma is a verrucous tumour with condylomatous appearance and viral changes, including koilocytosis (perinuclear cytoplasmic clearing with peripheral condensation of the cytoplasm) and significant cytonuclear changes, such as irregular nuclear contours, hyperchromasia and binucleation/ multinucleation (e, f). Differential diagnoses of verrucous carcinoma includes verrucous hyperplasia (g, h) or pseudo-epitheliomatous hyperplasia (i, j). Squares indicate locations of pictures shown in the right panels.

did not show any staining or showed sporadically cells with weak, mainly cytoplasmic staining.

The high-risk HPV-positive verrucous carcinoma (HPV 35/45) and the verrucous hyperplasia containing skin HPV (HPV 4/8) were also negative for p16 ${ }^{\mathrm{INK} 4 \mathrm{~A}}$ staining.

p16 $6^{\mathrm{INK} 4 \mathrm{~A}}$ was also performed on both control condylomata acuminata. One showed a focal patchy staining pattern and the other was negative for $\mathrm{p} 16^{\mathrm{INK} 4 \mathrm{~A}}$.

\section{Discussion}

As a potential role of HPV in the development of verrucous carcinoma is still a matter of debate, we extensively explored the presence of HPV in 27 samples taken from the archives of the Department of Pathology of the VUMC and originally diagnosed as verrucous carcinoma. Testing for a total of $83 \mathrm{HPV}$ types, including both mucosal and cutaneous types, 

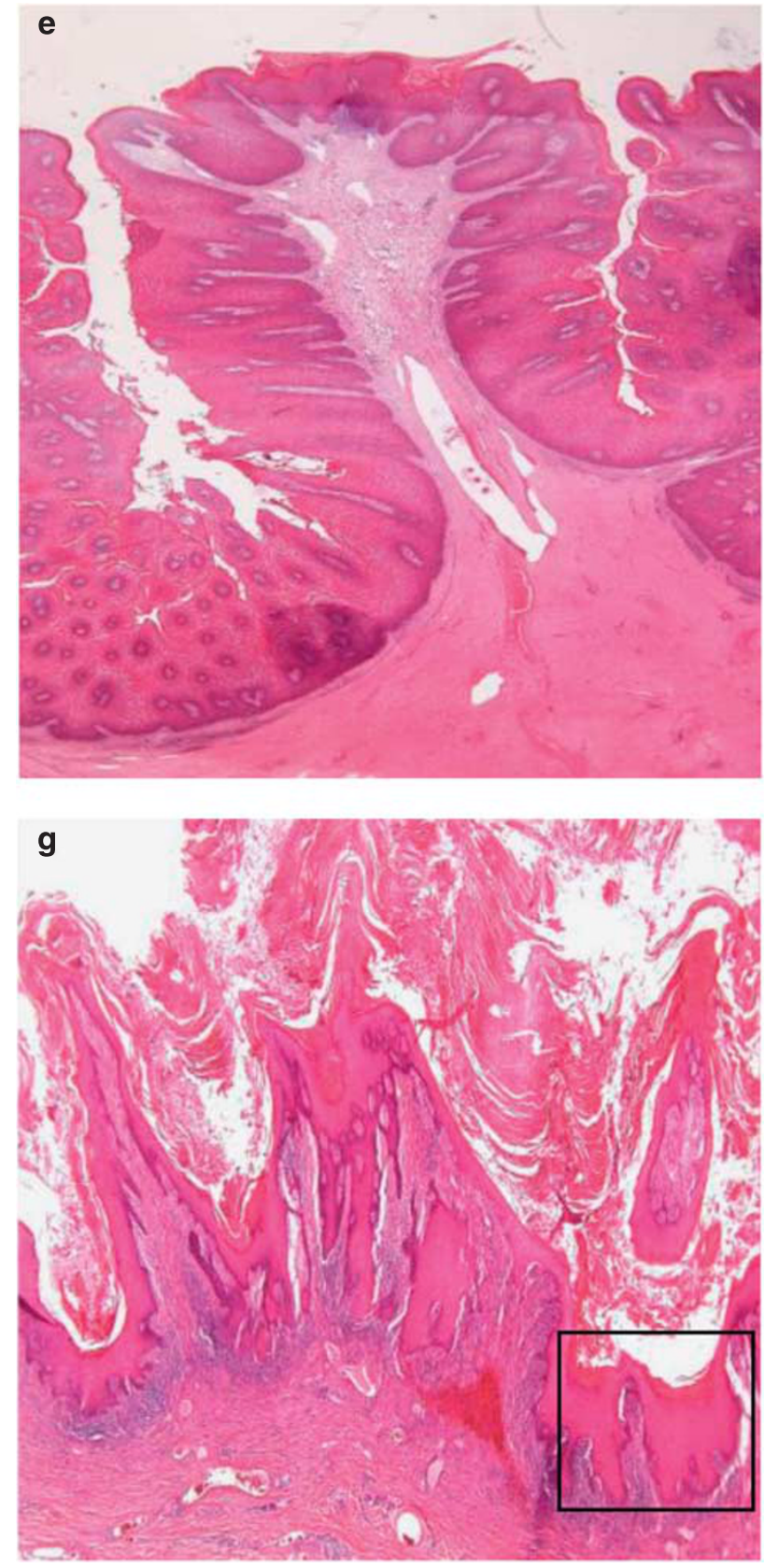

Figure 1 Continued.

revealed HPV positivity in $18.5 \%$ (5/27) of the verrucous tumours.

Careful histopathological revision without prior knowledge of the HPV status revealed 13 verrucous carcinomas, 5 verrucous tumours with focal stromal invasion being defined as invasive squamous cell carcinoma, 5 verrucous hyperplasias, 3 giant condylomas and 1 pseudoepitheliomatous hyperplasias. A double infection with high-risk HPV types (HPV 35 and 45) was detected in a verrucous carcinoma of the head and neck region, and a double infection with cutaneous HPV types (HPV 4 and 8) was found in a verrucous hyperplastic lesion of the penis. Hence, only 1 out of 13 (7.7\%)
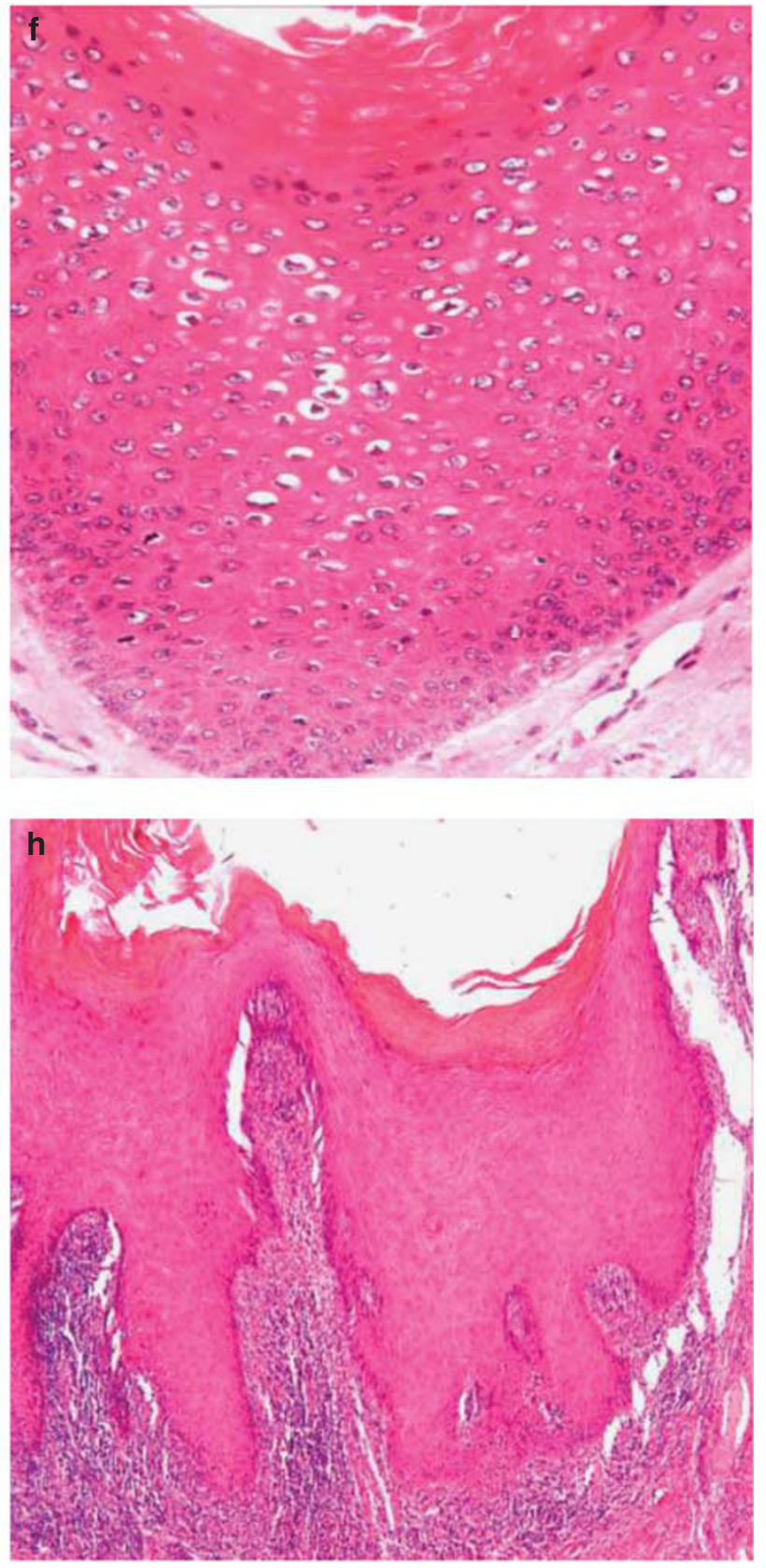

verrucous tumours revised as verrucous carcinoma was HPV positive. All three verrucous tumours that were revised as giant condylomas were positive for low-risk HPV: two giant condylomas of the penis were positive for HPV 6 and one giant condyloma of the vulva was positive for HPV 11 . These results suggest that HPV testing can help in the differentiation between verrucous carcinoma and giant condyloma in difficult cases, favouring verrucous carcinoma in case of HPV negativity and giant condyloma in case of HPV positivity.

The prevalence of HPV in verrucous carcinoma in our study was rather low, although the literature data are inconsistent. While some studies on vulvar 

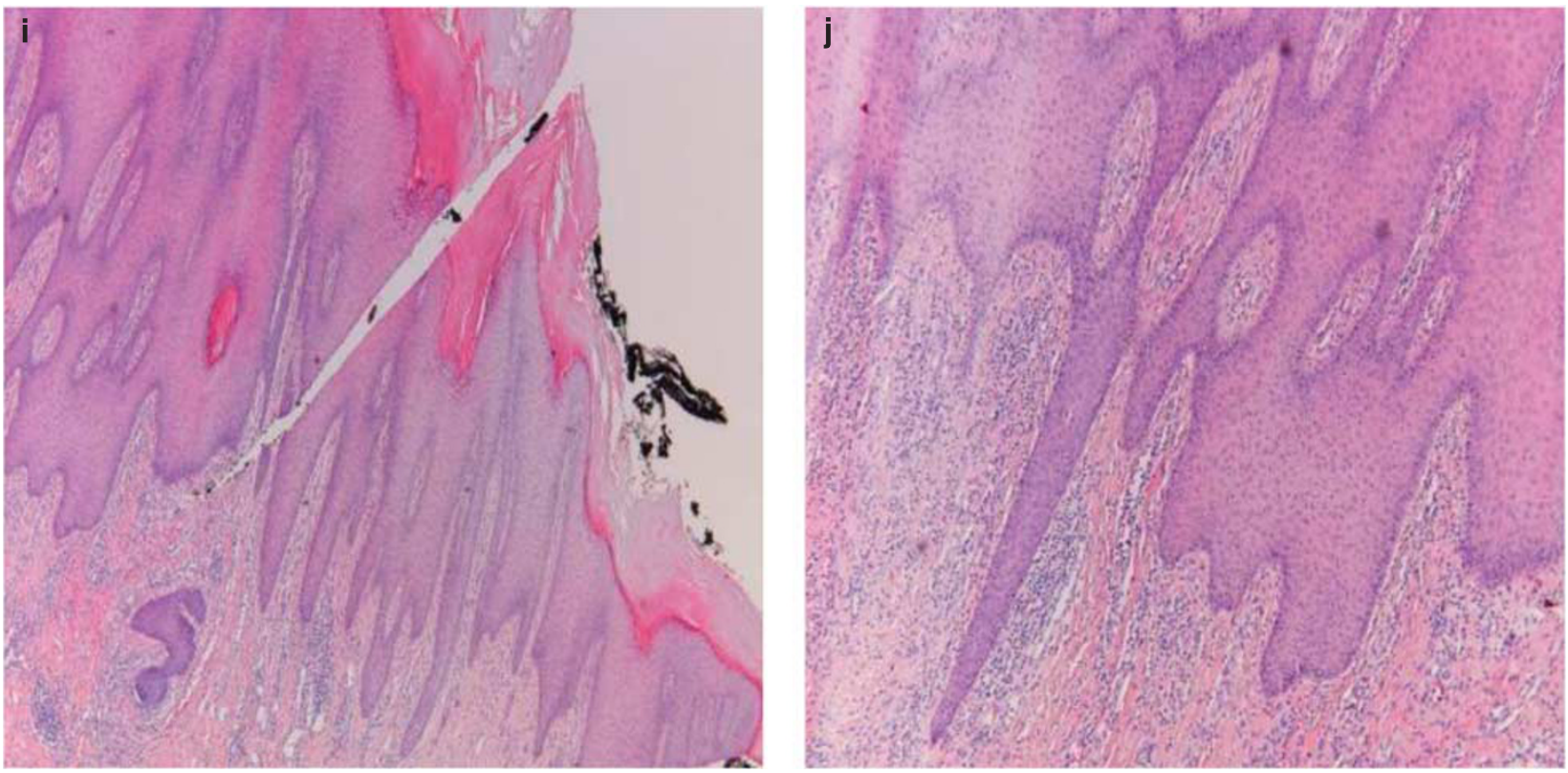

Figure 1 Continued.

and penile verrucous carcinoma have failed to detect HPV DNA, ${ }^{35-37}$ others have described HPV DNA positivity rates of up to $50 \% .^{2,17,38}$

Revision of the verrucous tumours, initially diagnosed as verrucous carcinoma, suggests that these lesions can be misclassified. Verrucous carcinoma and giant condylomas may share architectural and morphological similarities complicating the differential diagnosis between these entities. Moreover, stromal invasion can be very focal in a lesion with an appearance of a verrucous carcinoma in the bulk of the tumour. However, it has been accepted that tumours with stromal invasion should be classified as invasive squamous cell carcinoma. ${ }^{2,39}$ In addition, as known from the literature, the exact distinction between verrucous hyperplasia and verrucous carcinoma is not clearcut and the exact criteria are lacking. ${ }^{3,40}$

Previous studies concluded that verrucous carcinoma from mucosal areas are related to mucosal HPV types and verrucous carcinoma located in cutaneous areas are not specifically linked to any specific group of HPV. ${ }^{41}$ In this study, we found that mucosal types were indeed restricted to mucosal lesions, that is, high-risk HPV in a verrucous carcinoma of the head and neck region and low-risk HPV types in giant condylomas of the anus and vulva, whereas cutaneous HPV types were detected in a verrucous hyperplastic lesion of the penis.

Several hypotheses have been proposed to explain a potential role of HPV infection in the development of verrucous carcinoma. For high-risk HPV types, it has been well established that the viral genes $E 6$ and E7 drive malignant transformation in case of cervical squamous cell carcinomas and adenocarcinomas. ${ }^{42}$ For verrucous carcinoma arising from the head and neck region, it has been reported that high-risk HPV are opportunistic viruses enhancing other carcinogenic factors such as tobacco or alcohol. ${ }^{43,44}$ In case of low-risk HPV types, sequence variations increasing their transforming potential has been described. ${ }^{26}$ Moreover, it has also been suggested that malignant transformation may be more related to the host response to the HPV infections than to the virus itself. $^{11}$

Giant condylomas have been considered as a different spectrum of the same entity as verrucous carcinoma, ${ }^{27,45}$ suggesting that a chronic irritated condylomata caused by a low-risk HPV could evolve to a more aggressive lesion as a verrucous carcinoma. ${ }^{38,46}$

RT-PCR analysis of the verrucous carcinoma testing positive for low-risk HPV revealed E6 mRNA expression in all of them, indicating that the virus is actively present. However, the absence of diffuse p16 $6^{\mathrm{INK} 4 \mathrm{~A}}$ staining is in agreement with earlier observations that low-risk HPV do not interfere with the cell cycle, as is seen upon pRb inactivation by high-risk HPVE7. The same pattern (E6 mRNA expression and the absence of diffuse p16 ${ }^{\text {INK4A }}$ positivity) was observed in the two control condylomata acuminata analysed, strengthening the hypothesis that condylomata acuminata, giant condyloma and verrucous carcinoma belong to a different spectrum of the same entity. Also, the fact that the oral verrucous carcinoma testing positive for HPV35 and 45 was p16 $16^{\mathrm{INK} 4 \mathrm{~A}}$ negative indicates that the virus is most likely not involved in the development of the oral verrucous carcinoma. Recent studies have proposed diffuse $\mathrm{p} 16^{\text {INK4A }}$ staining as the first step in an algorithm for detecting clinically relevant HPV infections in squamous cell 
a

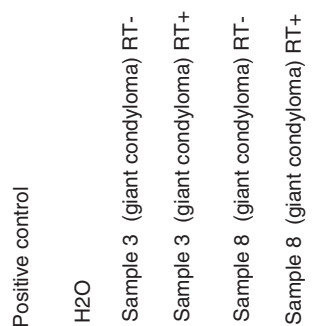

b

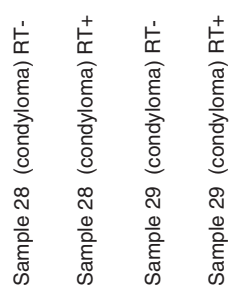

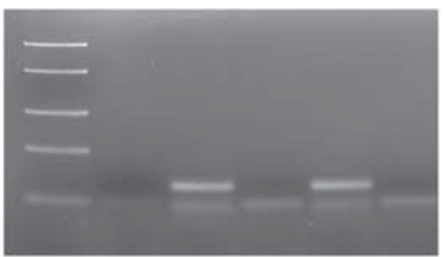

U1A

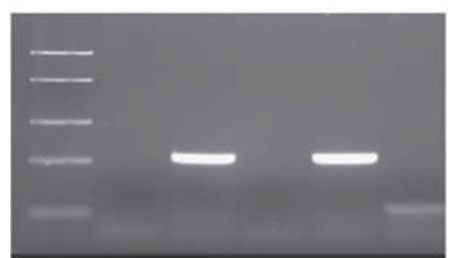

C
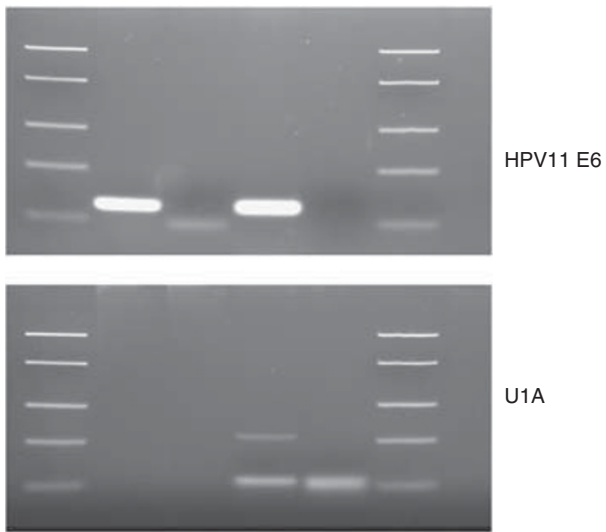

Figure 2 Agarose gel read-outs of reverse transcriptase polymerase chain reactions (PCRs) determining mRNA expression of human papillomavirus (HPV) 6 and HPV $11 E 6$ and the housekeeping gene U1A, respectively, in low-risk HPV-positive samples and condylomata acuminata. (a) HPV 6 E6 and U1A mRNA expression in two giant condylomas that were HPV 6 DNA positive (b). HPV 6 E6 and U1A mRNA expression in two condylomata acuminata (c). HPV 11 E6 and U1A mRNA expression in a vulvar giant condyloma. RT + and RT- represent the results with and without reverse transcriptase added to the reverse transcriptase reaction before PCR.

carcinoma of head and neck, as the overexpression of $\mathrm{p} 16^{\mathrm{INK} 4 \mathrm{~A}}$ is strongly related with the viral oncogene activity. ${ }^{47}$ The absence of a causal relation in the oral verrucous carcinoma is also supported by the fact that the PCR signals obtained for HPV35 and 45 DNA were rather weak.

From these data, we conclude that HPV is unlikely to be causally related to verrucous carcinoma development. In addition, testing for low-risk HPV may aid in histopathological diagnosis of lesions suspected of verrucous carcinoma as the low-risk HPV-positive cases are most likely to represent giant condylomas.

\section{Disclosure/conflict of interest}

The authors declare no conflict of interest. 


\section{References}

1 Ackerman LV. Verrucous carcinoma of the oral cavity. Surgery 1948;23:670-678.

2 Mercer SE, Khalil D, Emanuel PO, Goldenberg G. Verrucous carcinoma masquerading as a giant fibroepithelial polyp. Int J Surg Pathol 2010;18:347-351.

3 van der Waal I, Reichart PA. Oral proliferative verrucous leukoplakia revisited. Oral Oncol 2008;44:719-721.

4 de Spindula-Filho JV, da Cruz AD, Oton-Leite AF, et al. Oral squamous cell carcinoma versus oral verrucous carcinoma: an approach to cellular proliferation and negative relation to human papillomavirus (HPV). Tumour Biol 2011;32:409-416.

5 Fujita S, Senba M, Kumatori A, et al. Human papillomavirus infection in oral verrucous carcinoma: genotyping analysis and inverse correlation with p53 expression. Pathobiology 2008;75:257-264.

6 Neville BW, Day TA. Oral cancer and precancerous lesions. CA Cancer J Clin 2002;52:195-215.

7 Alkan A, Bulut E, Gunhan O, Ozden B. Oral verrucous carcinoma: a study of 12 cases. Eur J Dent 2010;4: 202-207.

8 Brash DE, Rudolph JA, Simon JA, et al. A role for sunlight in skin cancer: UV-induced p53 mutations in squamous cell carcinoma. Proc Natl Acad Sci USA 1991;88:10124-10128.

9 de Koning MN, Quint WG, Pirog EC. Prevalence of mucosal and cutaneous human papillomaviruses in different histologic subtypes of vulvar carcinoma. Mod Pathol 2008;21:334-344.

10 Boshart M, zur Hausen H. Human papillomaviruses in Buschke-Lowenstein tumors: physical state of the DNA and identification of a tandem duplication in the noncoding region of a human papillomavirus 6 subtype. J Virol 1986;58:963-966.

11 Cuesta KH, Palazzo JP, Mittal KR. Detection of human papillomavirus in verrucous carcinoma from HIV-seropositive patients. J Cutan Pathol 1998;25: 165-170.

12 de Villiers EM, Fauquet C, Broker TR, Bernard HU, zur Hausen H. Classification of papillomaviruses. Virology 2004;324:17-27.

13 Asgari MM, Kiviat NB, Critchlow CW, et al. Detection of human papillomavirus DNA in cutaneous squamous cell carcinoma among immunocompetent individuals. J Invest Dermatol 2008;128:1409-1417.

14 Munoz N, Bosch FX, de Sanjose S, et al. Epidemiologic classification of human papillomavirus types associated with cervical cancer. N Engl J Med 2003; 348:518-527.

15 Schiffman M, Castle PE, Jeronimo J, et al. Human papillomavirus and cervical cancer. Lancet 2007;370: 890-907.

16 Heideman DA, Waterboer T, Pawlita M, et al. Human papillomavirus-16 is the predominant type etiologically involved in penile squamous cell carcinoma. J Clin Oncol 2007;25:4550-4556.

17 Noel JC, Vandenbossche M, Peny MO, et al. Verrucous carcinoma of the penis: importance of human papillomavirus typing for diagnosis and therapeutic decision. Eur Urol 1992;22:83-85.

18 Rubin MA, Kleter B, Zhou M, et al. Detection and typing of human papillomavirus DNA in penile carcinoma: evidence for multiple independent pathways of penile carcinogenesis. Am J Pathol 2001; 159:1211-1218.
19 zur Hausen H, Meinhof W, Scheiber W, Bornkamm GW. Attempts to detect virus-specific DNA in human tumors. I. Nucleic acid hybridizations with complementary RNA of human wart virus. Int J Cancer 1974;13:650-656.

20 zur Hausen H. Condylomata acuminata and human genital cancer. Cancer Res 1976;36:794.

21 Alos L, Moyano S, Nadal A, et al. Human papillomaviruses are identified in a subgroup of sinonasal squamous cell carcinomas with favorable outcome. Cancer 2009;115:2701-2709.

22 El-Mofty SK, Lu DW. Prevalence of high-risk human papillomavirus DNA in nonkeratinizing (cylindrical cell) carcinoma of the sinonasal tract: a distinct clinicopathologic and molecular disease entity. Am J Surg Pathol 2005;29:1367-1372.

23 Lu DW, El-Mofty SK, Wang HL. Expression of p16, Rb, and p53 proteins in squamous cell carcinomas of the anorectal region harboring human papillomavirus DNA. Mod Pathol 2003;16:692-699.

24 Djurdjevic S, Segedi D, Vejnovic T, Vejnovic J. Modern approach to classification of precancerous conditions and vulvar dystrophy. Med Pregl 1995;48:399-404.

25 Schwartz RA. Verrucous carcinoma of the skin and mucosa. J Am Acad Dermatol 1995;32:1-21.

26 Grassmann K, Wilczynski SP, Cook N, et al. HPV6 variants from malignant tumors with sequence alterations in the regulatory region do not reveal differences in the activities of the oncogene promoters but do contain amino acid exchanges in the E6 and E7 proteins. Virology 1996;223:185-197.

27 Bogomoletz WV, Potet F, Molas G. Condylomata acuminata, giant condyloma acuminatum (BuschkeLoewenstein tumour) and verrucous squamous carcinoma of the perianal and anorectal region: a continuous precancerous spectrum? Histopathology 1985; 9:1155-1169.

28 de Roda Husman AM, Walboomers JM, van den Brule AJ, et al. The use of general primers GP5 and GP6 elongated at their $3^{\prime}$ ends with adjacent highly conserved sequences improves human papillomavirus detection by PCR. J Gen Virol 1995;76(Part 4): 1057-1062.

29 Jacobs MV, Snijders PJ, van den Brule AJ, et al. A general primer GP5+/GP6(+)-mediated PCR-enzyme immunoassay method for rapid detection of 14 highrisk and 6 low-risk human papillomavirus genotypes in cervical scrapings. J Clin Microbiol 1997;35: 791-795 .

30 van den Brule AJ, Pol R, Fransen-Daalmeijer N, et al. GP5+/6+ PCR followed by reverse line blot analysis enables rapid and high-throughput identification of human papillomavirus genotypes. J Clin Microbiol 2002;40:779-787.

31 Kleter B, van Doorn LJ, Ter Schegget J, et al. Novel short-fragment PCR assay for highly sensitive broadspectrum detection of anogenital human papillomaviruses. Am J Pathol 1998;153:1731-1739.

32 Kleter B, van Doorn LJ, Schrauwen L, et al. Development and clinical evaluation of a highly sensitive PCRreverse hybridization line probe assay for detection and identification of anogenital human papillomavirus. J Clin Microbiol 1999;37:2508-2517.

33 Brink AA, Lloveras B, Nindl I, et al. Development of a general-primer-PCR-reverse-line-blotting system for detection of beta and gamma cutaneous human papillomaviruses. J Clin Microbiol 2005;43:5581-5587. 
34 Heideman DA, Snijders PJ, Bloemena E, et al. Absence of tpr-met and expression of c-met in human gastric mucosa and carcinoma. J Pathol 2001;194:428-435.

35 Gualco M, Bonin S, Foglia G, et al. Morphologic and biologic studies on ten cases of verrucous carcinoma of the vulva supporting the theory of a discrete clinicopathologic entity. Int J Gynecol Cancer 2003;13: 317-324.

36 Nascimento AF, Granter SR, Cviko A, et al. Vulvar acanthosis with altered differentiation: a precursor to verrucous carcinoma? Am J Surg Pathol 2004;28:638-643.

37 Masih AS, Stoler MH, Farrow GM, et al. Penile verrucous carcinoma: a clinicopathologic, human papillomavirus typing and flow cytometric analysis. Mod Pathol 1992;5:48-55.

38 Kondi-Paphitis A, Deligeorgi-Politi H, Liapis A, Plemenou-Frangou M. Human papilloma virus in verrucus carcinoma of the vulva: an immunopathological study of three cases. Eur J Gynaecol Oncol 1998;19:319-320.

39 Santoro A, Pannone G, Contaldo M, et al. A troubling diagnosis of verrucous squamous cell carcinoma ('the bad kind' of keratosis) and the need of clinical and pathological correlations: a review of the literature with a case report. J Skin Cancer 2011;2011:370605.

40 Lin HP, Wang YP, Chiang CP. Expression of p53, MDM2, p21, heat shock protein 70, and HPV 16/18 E6 proteins in oral verrucous carcinoma and oral verrucous hyperplasia. Head Neck 2011;33:334-340.

41 Dubina M, Goldenberg G. Viral-associated nonmelanoma skin cancers: a review. Am J Dermatopathol 2009; 31:561-573.

42 Scheffner M, Werness BA, Huibregtse JM, et al. The E6 oncoprotein encoded by human papillomavirus types 16 and 18 promotes the degradation of p53. Cell 1990;63:1129-1136.

43 Adler-Storthz K, Newland JR, Tessin BA, et al. Human papillomavirus type 2 DNA in oral verrucous carcinoma. J Oral Pathol 1986;15:472-475.

44 Eisenberg E, Rosenberg B, Krutchkoff DJ. Verrucous carcinoma: a possible viral pathogenesis. Oral Surg Oral Med Oral Pathol 1985;59:52-57.

45 Creasman C, Haas PA, Fox TA, Balazs M. Malignant transformation of anorectal giant condyloma acuminatum (Buschke-Loewenstein tumor). Dis Colon Rectum 1989;32:481-487.

46 Djurdjevic S, Devaja O, Hadzic B. Malignant potential of gigantic condylomatous lesions of the vulva. Eur J Gynaecol Oncol 1999;20:63-66.

47 Smeets SJ, Hesselink AT, Speel EJ, et al. A novel algorithm for reliable detection of human papillomavirus in paraffin embedded head and neck cancer specimen. Int J Cancer 2007;121:2465-2472. 